Article

\title{
Assessment of the Role of Local Strawberry Rhizosphere- Associated Streptomycetes on the Bacterially-Induced Growth and Botrytis cinerea Infection Resistance of the Fruit
}

\author{
Karen L. Eccleston, Peter R. Brooks and D. İpek Kurtböke * \\ Faculty of Science, Health and Education, University of the Sunshine Coast, Maroochydore DC, \\ Queensland, 4558, Australia; E-Mails: ecclestonkl@hotmail.com (K.L.E.); pbrooks@usc.edu.au (P.R.B.) \\ * Author to whom correspondence should be addressed; E-Mail: ikurtbok@usc.edu.au; \\ Tel.: +61-07-5430-2819; Fax: +61-07-5430-2881.
}

Received: 22 November 2010 / Accepted: 10 December 2010 / Published: 22 December 2010

\begin{abstract}
The future need for sustainable agriculture will be met in part by wider use of biological control of plant pathogens over conventional fungicides hazardous to the environment and to public health. Control strategies involving both (i) direct use of microorganisms antagonistic to the phytopathogen, and (ii) use of bioactive compounds (secondary metabolites/antibiotic compounds) from microorganisms on the phytopathogen were both adapted in order to investigate the ability of streptomycetes isolated from the rhizosphere of strawberry plants to promote the growth of the fruit and suppress Botrytis cinerea causing strawberry rot on the Sunshine Coast, Queensland, Australia. In vitro studies showed that 25/39 streptomycetes isolated from strawberry field soils inhibited $B$. cinerea growth by antifungal activity, ranging from antibiosis to volatile compound production. However, when non-volatile antifungal compounds were extracted and applied aerially to the actively growing strawberry fruits infected with $B$. cinerea, a significant disease reduction was not recorded. On the other hand, plant and fruit growth was promoted by the presence of actively growing streptomycetes in container media. Findings might indicate that live streptomycete inoculum can be used as growth promoting agent in container media for this economically important crop.
\end{abstract}

Keywords: strawberry; Botrytis cinerea; streptomycetes; biological control; growth promotion 


\section{Introduction}

Currently, the strawberry industry in Australia has an economic value of \$250 million with a farm gate value of $\$ 100$ million supporting 700 producers, employing 3,000 full-time and 15,000 casual workers. This makes it important for the horticultural industry, with approximately $30 \%$ of current production taking place in Queensland during the winter period and 70\% of production in Victoria, Tasmania, New South Wales and Western Australia during the spring/autumn period [1]. Botrytis cinerea, Colletotrichum gloeosporioides and Phytophthora cactorumare are the three major strawberry pathogens and $B$. cinerea has proved extremely difficult to control, due to its complex epidemiology andvarious pathways of infection. It has the ability to rapidly develop fungicide resistance, with resistant strains reported in Victoria, Australia [2].

Under cultivation, B. cinerea of strawberries is generally managed with an integrated program of synthetic chemical fungicides and cultural practices, such as removing infected fruit and leaf material from the plants [3]. Currently, the strains of $B$. cinerea resistant to two fungicide groups, benzimidazoles and dicarboximide are of particular concern as these chemicals are recommended and widely utilized for controlling disease on strawberries in Australia [4,5]. Biological control might be an alternative route to inhibit this pathogen by reducing the use of some chemical fungicides, which may in turn help to combat resistance problems often experienced with chemical control [6,7].

Extensive research into fungal and bacterial antagonists as potential biocontrol agents of $B$. cinerea has been carried out over the past 50 years in various countries throughout the world, including Australia. However, very few commercially viable biocontrol products have been released on the agronomic market, especially when compared to the number of synthetic based fungicides available for pathogen control [8-10]. Investigations of fungal and bacterial antagonists of $B$. cinerea have concentrated mainly on Trichoderma, Gliocladium, Pseudomonas, and Bacillus species [11]. Continued research on these antagonists as well as definition of the activities of new ones will aid in the formulation of commercially viable control products to reduce fungicide applications to crops.

The investigation described below targeted streptomycete species from strawberry field soils to determine whether these isolates would produce diffusible and/or volatile antifungal compounds inhibitory towards $B$. cinerea in vitro. The study further investigated whether live streptomycete inoculum incorporated into container media used to grow the fruit or the chemical extracts of the streptomycete fermentation products would reduce disease incidences caused by $B$. cinerea and induce growth promotion to the fruit.

\section{Experimental Section}

\subsection{Isolation of the Pathogen}

Commercial strawberry farmers commonly report B. cinerea infections in the Sunshine Coast Area. Isolations of the pathogen were therefore conducted from four cultivars (cultivars Camarosa, Selva, Parker and Kabala) collected from a commercial strawberry farm in the region. Infected fruit portions $\left(\sim 5 \mathrm{~mm}^{2}\right)$ were placed centrally onto malt yeast extract agar (MYA) [12] containing streptomycin $(50 \mathrm{ug} / \mathrm{mL})$ to prevent bacterial growth, and incubated at $22{ }^{\circ} \mathrm{C} \pm 2{ }^{\circ} \mathrm{C}$ for four days. The resulting 18 fungal isolates were purified onto the MYA and were identified and deposited at the Herbarium 
(BRIP), Queensland Department of Primary Industries, Indooroopilly, Australia. Strain BRIP 28032-14 which was the most aggressive strain colonizing the fruit in laboratory trials, was selected as the test pathogen for this study to determine the effects of selected streptomycete antagonists on B. cinerea.

\subsection{Isolation and Antifungal Screening of Streptomycetes against the Pathogen}

Soil samplesaseptically collected to a depth of $10 \mathrm{~cm}$ within the rhizosphere of each strawberry cultivar were used for streptomycete isolations using Starch-casein agar [13] supplemented with antifungal antibiotics (Nystatin and Cycloheximide, $50 \mathrm{ug} / \mathrm{mL}$, Sigma) and incubated at $28 \pm 2{ }^{\circ} \mathrm{C}$ for seven days. Selected streptomycete isolates were purified on Oatmeal agar [14] and incubated at $28 \pm 2{ }^{\circ} \mathrm{C}$ for 10 days. Tentatively identified streptomycete isolates $[15,16]$ were then stored in $20 \%$ glycerol at $-20^{\circ} \mathrm{C} \pm 2{ }^{\circ} \mathrm{C}[17]$.

Streptomycete isolates that showed antagonistic properties towards $B$. cinerea from the dual culture assay [18] described above were selected for further study (Table 1). A dialysis membrane overlay technique was also used [19] to confirm the production of diffusible antifungal metabolites from the streptomycete isolates inhibitory towards B. cinerea. Potato Dextrose Agar (Oxoid) (PDA) plates untreated with the streptomycete antagonists and inoculated with $B$. cinerea agar plugs served as the control. The production of volatile inhibitory compounds against $B$. cinerea by the streptomycete isolates was studied using the volatile compound production assay [20].

Table 1. Details of streptomycetes isolated from the strawberry rhizosphere soil.

\begin{tabular}{lcl}
\hline Cultivar & $\begin{array}{c}\text { Total number } \\
\text { of isolates }\end{array}$ & \multicolumn{1}{c}{ Isolate codes } \\
\hline Selva & 8 & $\mathrm{~S} 1 \neq, \mathrm{S} 2, \mathrm{~S} 5 \neq, \mathrm{S} 6, \mathrm{~S} 7, \mathrm{~S} 8, \mathrm{~S} 9, \mathrm{~S} 10$ \\
Kabala & 9 & $\mathrm{~K} 1 \neq, \mathrm{K} 2 \neq, \mathrm{K} 3 \neq, \mathrm{K} 4 \neq, \mathrm{K} 5 \neq, \mathrm{K} 6 \neq, \mathrm{K} 7, \mathrm{~K} 8 \neq$ \\
Camarosa & 16 & $\mathrm{C} 1, \mathrm{C} 2 \neq, \mathrm{C} 3 \neq, \mathrm{C} 4 \neq, \mathrm{C} 6 \neq, \mathrm{C} 7 \neq, \mathrm{C} 8, \mathrm{C} 9, \mathrm{C} 10 \neq$ \\
& & $\mathrm{CN} 1 \neq, \mathrm{CN} 2 \neq, \mathrm{CN} 3 \neq, \mathrm{CN} 4 \neq, \mathrm{CN} 5 \neq, \mathrm{CN} 6 \neq, \mathrm{CN} 7 \neq$ \\
Parker & 7 & $\mathrm{P} 1, \mathrm{P} 2 \neq, \mathrm{P} 3, \mathrm{P} 4 \neq, \mathrm{P} 5, \mathrm{P} 6, \mathrm{P} 7 \neq$ \\
USC isolates* & & $\mathrm{S} 4 \neq, \mathrm{S} 21 \neq$ \\
\hline
\end{tabular}

*Antifungal streptomycetes selected from the USC Microbial Library and were previously isolated from container media soil used to grow cut flowers in the region, $\neq$ Bioactive isolates.

In both tests, the colony diameters $(\mathrm{mm})$ of $B$. cinerea were measured on the plates treated with and without the streptomycetes following incubation. A one-way analysis of variance (ANOVA) (performed on SPSS version 10.1 for Windows) was performed to test for significant differences between the colony diameters of $B$. cinerea from treated and control plates. If a significant ANOVA result was calculated, significant differences between means were determined by Duncan's multiple-range test (DMRT) at $P=0.05$.

\subsection{Antifungal Compound Extractions and Purifications}

Four selected streptomycete strains (S21, S4, C3 and K5), which displayed the greatest inhibitory effect on the above-mentioned assays, were prepared by evenly streaking spores from 7-10 day old cultures over the 12 replicated oatmeal agar plates, and incubating at $28 \pm 2{ }^{\circ} \mathrm{C}$ for 14 days. Following 
the incubation, diffused compounds were extracted by using two different solvents from equally divided plate contents [21]. Dried and concentrated extracts were transferred to small glass vials and stored at $-20{ }^{\circ} \mathrm{C}$ until required. The concentrated extracts were then assayed for antifungal activity utilizing a cup-plate method [18]. Extracts were also tested to determine their inhibitory activity against the spore germination of $B$. cinerea [22].

Fermentation metabolites of streptomycetes were studied using the methods described by Kurtboke et al. [23]. The methanol extract obtained from isolate $\mathrm{S} 4,(\mathrm{~S} 4-\mathrm{MeOH})$, proved to have a strong inhibitory action against $B$. cinerea. The crude extract was fractionated on compound polarity by passing through a $\mathrm{C}_{18}$ solid phase extraction (SPE) tube (Supelco LC-18 $6 \mathrm{~mL}$ ). The SPE tube was conditioned by running $3 \mathrm{~mL}$ of $\mathrm{MeOH}$ through the tube, followed by $3 \mathrm{~mL}$ of distilled water. The $\mathrm{S} 4-\mathrm{MeOH}$ extract, $4 \mathrm{~mL}$, (turbid, deep red) was run into tube, followed by three washes; $3 \mathrm{~mL}$ with $\mathrm{H}_{2} \mathrm{O}$ producing a light cream slightly turbid fraction (S4-A), $3 \mathrm{~mL}$ with $1 / 3 \mathrm{MeOH} / \mathrm{H}_{2} \mathrm{O}$ producing a light brown fraction (S4-B) and $3 \mathrm{~mL}$ with $\mathrm{MeOH}$, producing a bright red fraction (S4-C). All three fractions were vacuum evaporated and assayed for activity utilising the methods described above. The most active fraction, S4-C, was further purified by preparative high performance liquid chromatography (HPLC) utilising a Perkin Elmer series 200 pump equipped with a diode array detector, separating on a $100 \mathrm{~mm} \times 10$ Omnifit $\mathrm{RP} \mathrm{C}_{18}$ column, with detector parameters set at $205 \mathrm{~nm}$ (Channel A) and $260 \mathrm{~nm}$ (Channel B). The mobile phase solvents were prepared from HPLC grade acetonitrile $(\mathrm{ACN})$ and Milli-Q water $\left(\mathrm{H}_{2} \mathrm{O}\right)$. Solvent A consisted of 25/75 ACN/ $\mathrm{H}_{2} \mathrm{O}$ and solvent B consisted of $75 / 25 \mathrm{ACN} / \mathrm{H}_{2} \mathrm{O}$. Total flow was maintained at $0.2 \mathrm{~mL}$ per minute, while maintaining $100 \%$ solvent A for 3 minutes. The flow rate was then increased to $1.0 \mathrm{~mL}$ per minute, while grading elution to 30/70 solvent A/B over 27 minutes, maintaining this for 4 minutes, before grading back to $100 \%$ solvent A over 6 minutes. The fraction visibly eluting as pink was collected and re-analysed as one peak by HPLC. The collected fraction was evaporated to $0.25 \mathrm{~mL}$ under reduced pressure on a Büchi Rotavapor, then transferred to a $2 \mathrm{~mL}$ vial and frozen at $-20{ }^{\circ} \mathrm{C}$. The sample was subsequently freeze-dried under vacuum in a dessicator which contained phosphorus pentoxide and anhydrous sodium carbonate in separate beakers. The dry extract was analysed in deutero $\left(\mathrm{d}_{4}\right)$-methanol by ${ }^{1} \mathrm{H}$ NMR (nuclear magnetic resonance) on a Varian UNITY $400 \mathrm{MHz}$ spectrometer, and by VG platform II electrospray LC-MS located at Griffith University, Queensland, Australia.

\subsection{Pot Trial}

A rye grass (cultivar Tetila) seed-based inoculum was prepared for selected streptomycete isolates for the pot trial conducted to grow strawberry plants in the presence and absence of the $B$. cinerea pathogen and the streptomycete antagonists [24]. Pasteurised soil $\left(0.35 \mathrm{~m}^{3}\right)$ for use in the pot trial was supplied by the Department of Primary Industries Maroochy Research Station located at Nambour, Queensland. The soil consisted of a mixture of $60 \%$ sand and $40 \%$ peat and was heat pasteurised with steam at $60{ }^{\circ} \mathrm{C}$ for $45 \mathrm{~min}$. Certified strawberry runners (cultivar Camarosa), grown in fumigated soil in Victoria, under the Victorian Strawberry Industry Certification Authority (VSICA), were obtained for pot trials. Prior to planting, strawberry runners were thoroughly cleaned in water to remove all dirt particles. A total of six treatments were prepared for the pot trial (Table 2). Treatments were arranged in a random block design, with plots consisting of the five treatments replicated 10 times. 
Table 2. Treatments used in the pot trial.

\begin{tabular}{ll}
\hline Pot treatment & Description \\
\hline Treatment-1 & Control \\
Treatment-2 & Disease control \\
Treatment-3 & C3-LP-EtOAc extract spray solution on aerial plant surfaces \\
Treatment-4 & Soil inoculated with non-inhibitory streptomycete isolates \\
& C1, C8, P6, S2 \\
Treatment-5 & Soil inoculated with inhibitory streptomycete isolates \\
& K3, K5, S4, S21 \\
Treatment-6 & $\begin{array}{l}\text { Rye grass seed inoculum control (Soil inoculated only with } \\
\text { sterilised rye grass seeds) }\end{array}$ \\
\hline
\end{tabular}

Disease index used to assess the effectivity of the above treatments: 1: No visible disease on fruit, 2: No greater than $1 / 4$ of fruit infected, 3 : No greater than $1 / 2$ of fruit infected, 4 : No greater than $3 / 4$ of fruit infected, 5: Whole fruit surface infected.

Control and aerial spray treatments were prepared by filling 10, $200 \mathrm{~mm}$ black plastic pots for each treatment with pasteurised soil to approx $1.5 \mathrm{~cm}$ from the pot $\operatorname{rim}$. Osmocote $\AA$ controlled release fertiliser was added to the soil surface as per manufacturer's specifications, prior to covering the pots with silver/black plastic (silver side up) and securing to the rim. A cross was cut into the plastic to expose the soil, with the strawberry runners planted using a metal planter to push the root system deep into the soil, leaving the leafless crown above soil level. For other treatments, inocula were introduced with a ratio of $0.84 \%(\mathrm{w} / \mathrm{w})$ into the potting soil. Plants were placed on plant stands in full sunlight and enclosed in wire netting to prevent fruit damage by wild animals and were irrigated by hosing every second day or when required. Treatments were arranged in a random block design, with plots consisting of the five treatments replicated 10 times [25].

\subsection{Pathogen Inoculations}

B. cinerea spores were harvested from MYA plates and the resulting spore suspension diluted into Tween $80(0.01 \%)$, with a final spore concentration of $1 \times 10^{5}$ spores $\mathrm{mL}^{-1}$. The spore suspension was sprayed onto the plants until runoff, concentrating on fruit, flowers and buds [18]. Treatment-1 (control) was sprayed only with sterilised Tween 80 (0.01\%) solution. Strawberry plants were returned to the enclosure and covered with clear plastic for $24 \mathrm{hrs}$ to promote humid conditions required for B. cinerea infection [26].

B. cinerea spores were inoculated onto the aerial surfaces of strawberry plants for Treatments 2,3 , 4,5 , and 6 utilising a handheld trigger action atomiser spray unit. The first inoculation event occurred approximately seven weeks after planting runners, when all plants were at the flowering and fruiting stage. Due to difficulties in establishing grey mould disease on strawberry plants, two additional inoculation events were performed at intervals of two weeks, following the initial inoculation event.

\subsection{Application of Antifungal Extract}

C3 was selected to produce large volumes of antifungal metabolite to be further tested to spray the plant aerially. A total of $20 \mathrm{~mL}$ of active extract was produced (following evaporation) using the 
solvent ethyl acetate, which was utilised for the preparation of an aerial spray treatment for the subsequent pot trial involving the pathogen.

The extract C3-LP-EtOAc was formulated into a solution by diluting the extract $(3.5 \mathrm{~mL})$ into a sterile Tween $80(0.1 \%)$ solution $(200 \mathrm{~mL})$. The extract solution was transferred into a handheld atomiser spray unit (as utilised for spore suspension inoculations) and applied to plants until runoff.

\subsection{Harvesting of Strawberry Fruit}

Ripe and/or severely diseased strawberry fruits were harvested from strawberry plants every four days. Each individual fruit harvested was weighed $(\mathrm{g})$, assessed for presence of disease, and any lesion/s of B. cinerea present measured in millimetres. Disease severity of strawberry fruits was rated with a disease index based on a scale from 1-5, adapted from the index described by Archbold et al. [27] (Table 2). Samples were taken from diseased fruit not showing classic symptoms and plated onto the MYA (incubated at room temperature approx. $22-24{ }^{\circ} \mathrm{C}$ for five days) to determine that $B$. cinerea was the actual causative agent. In addition, the wet and dry weights (drying at $60{ }^{\circ} \mathrm{C}$ for four days) of each strawberry plant were obtained for root and shoot portions [28].

A two-way ANOVA, performed on SPSS version 10.1 for Windows, was used to determine (i) differences in the harvested fruit weights between each treatment (g) and (ii) differences in the shoot, root, and combined shoot/root weights $(\mathrm{g})$ of the strawberry plants between each treatment. If a significant ANOVA result was calculated, significant differences between means were determined by DMRT at $P=0.05$.

\section{Results and Discussion}

\subsection{Detection of Antifungal Activity from Streptomycete Isolates}

In dual culture assays, most of the streptomycete isolates were observed to produce coloured extracellular compounds that diffused into the agar surrounding the inoculation site. These compounds were evident following the incubation of inoculated PDA plates before the addition of mycelium plugs of Botrytis cinerea. The observed inhibitory activity towards $B$. cinerea was not always associated with the production of these pigmented compounds by the isolates, however, 25 of the 39 streptomycete isolates were found to be capable of inhibiting B. cinerea growth (Table 2). Streptomycete isolates exhibiting various degrees of antagonistic activity towards the pathogen were selected for further screening of their activity in vitro and in vivo.

All streptomycete isolates were observed to produce pigmented metabolites, which diffused through the dialysis membrane into PDA during incubation. B. cinerea radial growth was significantly $(\mathrm{P}<0.05)$ inhibited by the diffused metabolites produced by 11 of the 12 streptomycete isolates when statistically compared to the control, as indicated by one-way ANOVA and DMRT results (Figure 1a).

Comparison of $B$. cinerea colony diameter measurements, obtained from the volatile compound production assay, proved that certain streptomycete isolates had a volatile inhibitory effect with a statistically significant $(\mathrm{P}<0.05)$ result obtained when analysed by one-way ANOVA. Streptomycete isolates $\mathrm{K} 3, \mathrm{~K} 5$, and S4 were found to be significantly different from the control and other isolates 
using DMRT $(\mathrm{P}=0.05)$ (Figure $1 \mathrm{~b}$ ), indicating that these isolates were able to produce inhibitory volatile metabolites towards $B$. cinerea.

Figure 1. B. cinerea colony diameter in (a) dialysis membrane assay (b) volatile compound production assay.

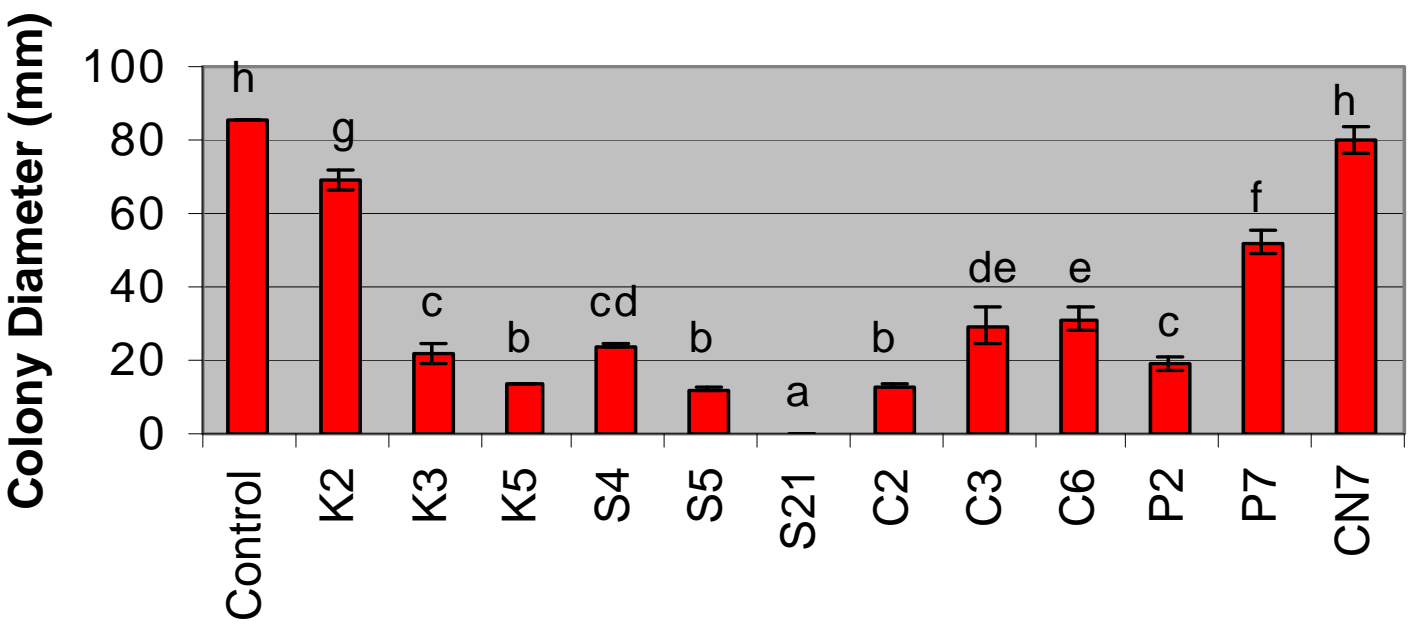

Isolate s

Bars represent the mean colony diameter of 4 replicate plates $( \pm \mathrm{SE})$. Measurements were square root transformed before analysis. Bars annotated with the same letter are not significantly $(\mathrm{P}>$ 0.05) different according to DMRT.

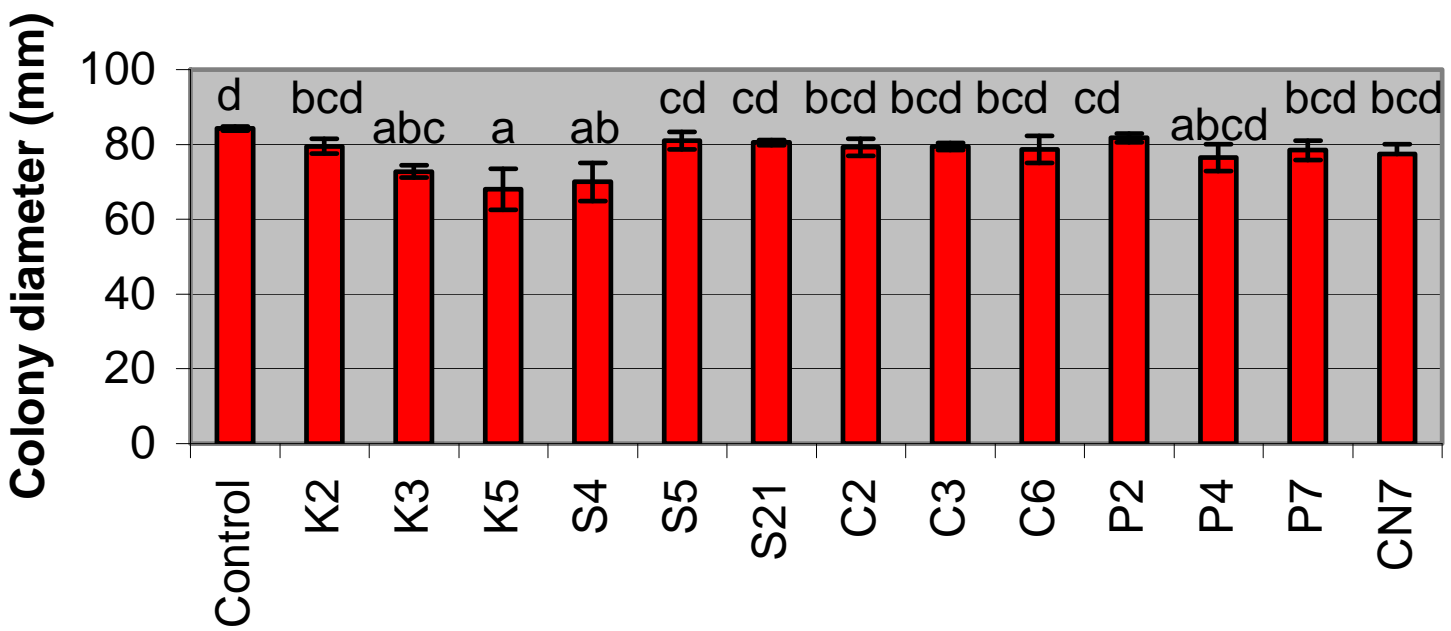

\section{Isolates}

Bars represent the mean colony diameter of 4 replicate plates $( \pm \mathrm{SE})$. Bars annotated with the same letter are not significantly $(\mathrm{P}>0.05)$ different according to DMRT.

\subsection{Extract Assays}

The assays for inhibitory activity against $B$. cinerea indicated that the extracts prepared using the solvent ethyl acetate retained the greatest activity, with S21-EtOAc and S4-EtOAc producing the greatest inhibition of $B$. cinerea (Table 3 ). The activity of extracts prepared with methanol were observed to have less inhibitory activity than the ethyl acetate extracts, with $\mathrm{C} 3-\mathrm{MeOH}$ and $\mathrm{K} 5-\mathrm{MeOH}$ losing all inhibitory action. The extracts prepared with methanol were also observed to possess a 
stronger colour than those prepared with ethyl acetate, particularly S4-MeOH and S21-EtOAc, which were deep turbid red and dark turbid brown, respectively.

Table 3. Inhibition of B. cinerea against antifungal metabolite extracts.

\begin{tabular}{lc}
\hline Extract & Inhibition Zone $(\mathrm{mm})$ \\
\hline S21-MeOH & 8.3 \\
S21-EtOAc & 11.0 \\
S4-MeOH & 9.0 \\
S4-EtOAc & 13.0 \\
C3-EtOAc & 7.0 \\
C3-MeOH & 0.0 \\
C3-LP-EtOAc & 6.6 \\
K5-MeOH & 0.0 \\
K5-EtOAc & 1.6 \\
\hline
\end{tabular}

Ethyl acetate has a lower polarity index $\left(\mathrm{P}^{1}=4.3\right)$ than methanol $\left(\mathrm{P}^{1}=6.6\right)$ [29], therefore ethyl acetate is more likely to extract compounds with lower polarity, whereas methanol will extract compounds with a greater polarity. Based on the polarity indexes of the solvents, isolates S21 and S4 were shown to produce both non-polar and polar bioactive compounds as the extracts prepared with both solvents were capable of inhibiting mycelial growth from B. cinerea cultures. Only ethyl acetate was able to extract bioactive compounds from isolates $\mathrm{C} 3$ and $\mathrm{K} 5$ with methanol extracts possessing no inhibitory activity, suggesting the bioactive metabolites produced by these streptomycete isolates were non-polar.

Following the $16 \mathrm{~h}$ incubation period, all extracts utilised in the spore germination assay were found to inhibit germination of $B$. cinerea spores when compared to the control. The results from the Kruskal-Wallis test indicated that there was a significant difference between the percentages of germinated spores recorded from the treatments, with a $\chi^{2}$ value of 18.615 at 6 degrees of freedom (df) and a significance level of $0.005(<$ set alpha level of 0.05$)$. As the Kruskal-Wallis test proved significant, the highest and lowest $R$ values were then compared. The control had the highest $R$ value (26.50), with treatments S4-MeOH, S4-EtOAc, and S21-EtOAc having the lowest $R$ value (10.50), indicating that these extract treatments had significantly lower spore germination percentages than the control.

The final purification of the active fraction from S4-MeOH, S4-C fraction, by HPLC resulted in the collection of a pink fraction, observed as a single chromatographic peak, which was dried and further analysed. Partial decomposition of the S4-C fraction on storage was apparent by the shift in colour from pink to orange and the appearance of two peaks in the LC-MS spectrum. Compound identification was not possible but the ${ }^{1} \mathrm{H}$ NMR was consistent with the presence of a monosaccharide, flavin like compound and valine fragments and the LC-MS provided molecular weights of 406 and 304 amu for the two compounds (Figure 2). 
Figure 2. LC-MS spectrum showing molecular weights of 406 and 304 amu for the two compounds detected with ${ }^{1} \mathrm{H}$ NMR.

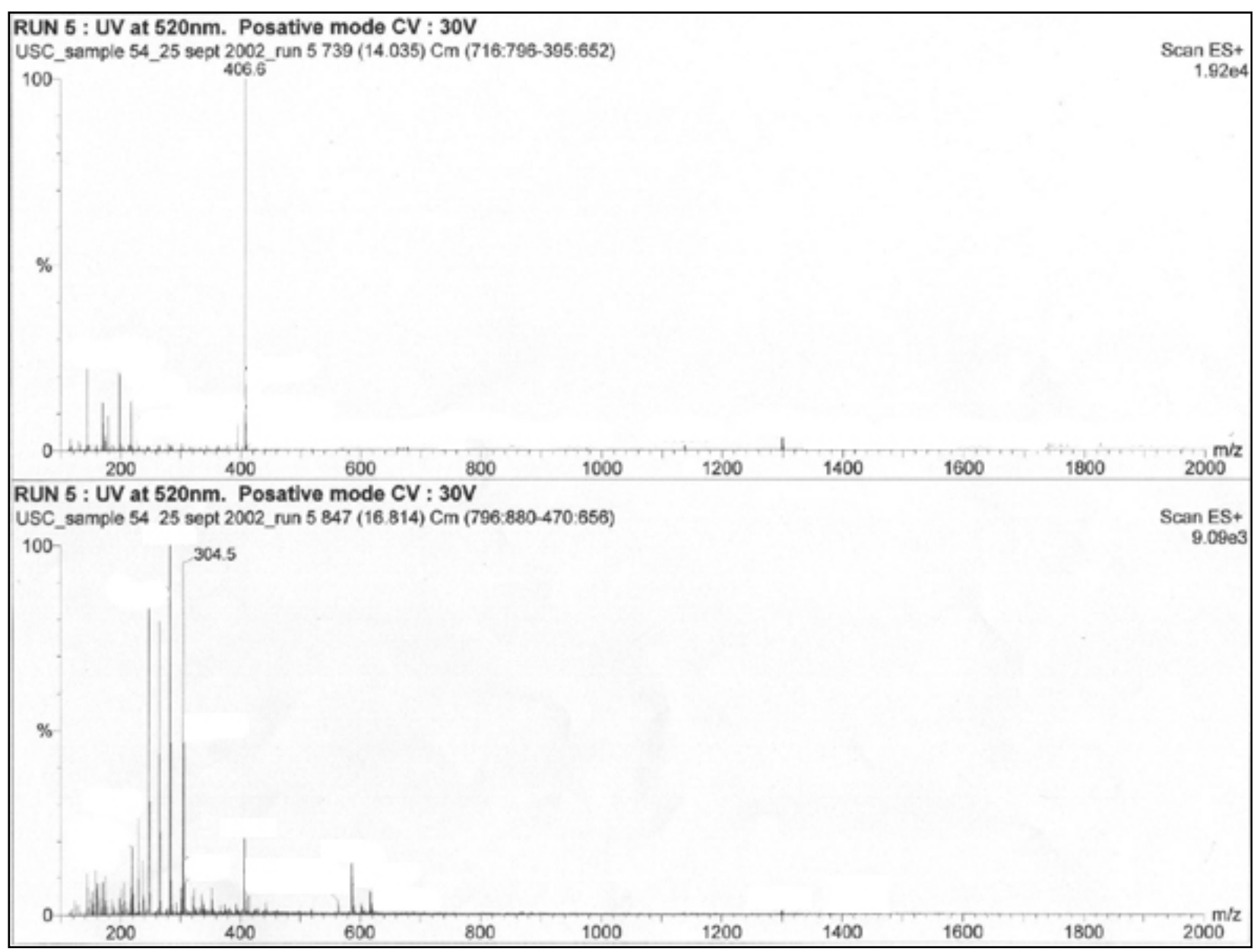

\subsection{Strawberry Pot Trials}

The fruit weights $(\mathrm{g})$ recorded from 14 harvesting occasions were found to be significantly $(\mathrm{P}<0.05)$ different between treatments, with no significant $(\mathrm{P}>0.05)$ difference found between blocks for pot Treatments 1 to 5. DMRT $(\mathrm{P}=0.05)$ determined that the mean fruit weight for the disease control, Treatment-2 (92.14 g) was significantly lower than the mean fruit weights obtained from the two treatments consisting of soil inoculated with streptomycete isolates, Treatment-4 (145.26 g) and Treatment-5 (140.16 g) (Figure 3). The mean weight of fruit harvested from the control, Treatment-1 (103.16 g) and the plants treated with the C3-LP-EtOAc crude extract, Treatment-3 (103.54 g) were not found to significantly differ from the other three pot treatments. 
Figure 3. Mean fruit weights per treatment.

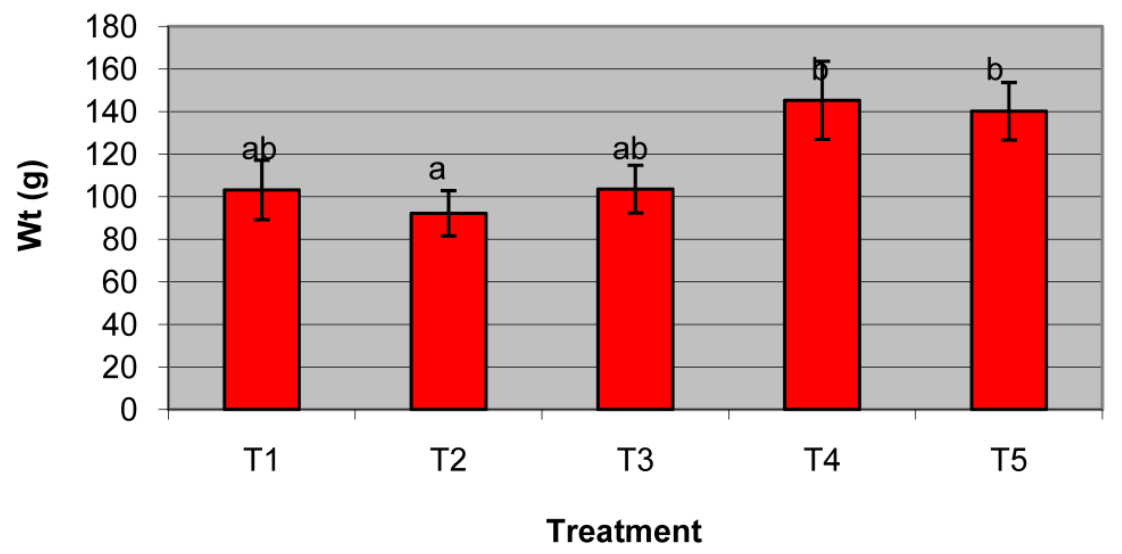

Bars represent the mean fruit weights for each treatment from 10 replicate plants (blocks) $( \pm \mathrm{SE})$. Bars annotated with the same letter are not significantly $(\mathrm{P}>0.05)$ different according to DMRT.

The incidence of each disease index ( 1 to 5), expressed as a percentage (\%) of the total fruit harvested for Treatments 1 to 5, determined that 91\% of fruit harvested from Treatment 1 showed no symptoms of $B$. cinerea incited disease (Table 4). Whereas, fruit harvested from the remaining treatments had a reduced proportion of fruit uninfected with B. cinerea, with $75 \%$ of fruit harvested from Treatments 2, 70\% from Treatment-3, 62\% from Treatment 4, and 70\% from Treatment 5 showing no symptoms of $B$. cinerea disease. These results therefore indicate that the application of $B$. cinerea spore suspension to Treatments 2, 3, 4, and 5 plants was responsible for the increase in strawberry fruits showing symptoms of $B$. cinerea infection. Comparing the incidence of diseased fruit (represented by Indexes 2 to 5) between Treatments 2, 3, 4, and 5 showed that $25 \%$ of fruit from Treatment 2 was recorded as showing symptoms consistent with $B$. cinerea infection whereas Treatment 3 recorded $30 \%$, Treatment 4 recorded $38 \%$ and Treatment 5 recorded $30 \%$ (Table 4 ). These results suggest that the three treatments $(3,4$, and 5), consisting of crude C3-LP extract or soil inoculated with streptomycete isolates, were unsuccessful in reducing the B. cinerea fruit infection. Comparing the percentages of severely infected fruit (represented by Index 5) provides further evidence of the inefficiency of the treatments. Treatments 3,4 , and 5 recoded $11 \%, 9 \%$, and $10 \%$ respectively, of severely diseased fruit, which was greater than the $5 \%$ recorded for Treatment 1 the 7\% recorded for Treatment 2 (Table 4). Overall Treatment 4 recorded the highest incidence of diseased fruit in comparison to the Treatments 3 and 5, which were the only two treatments consisting of or formulated from streptomycete isolates previously shown to be inhibitory to B. cinerea growth (Table 4).

Unlike the differences found between the fresh strawberry fruit weights for pot treatments, there were no significant differences $(\mathrm{P}>0.05)$ found between shoot, root and total dry plant weights in each treatment when analysed by 2-way ANOVA (Figure 4). 
Table 4. Overall incidence of B. cinerea infected fruit harvested from each pot treatment.

\begin{tabular}{|c|c|c|}
\hline Pot Treatment & Disease Index & Incidence (\%) \\
\hline \multirow{5}{*}{ Treatment-1 } & 1 & $91 \%$ \\
\hline & 2 & $2 \%$ \\
\hline & 3 & $0 \%$ \\
\hline & 4 & $2 \%$ \\
\hline & 5 & $5 \%$ \\
\hline \multirow[t]{5}{*}{ Treatment-2 } & 1 & $75 \%$ \\
\hline & 2 & $9 \%$ \\
\hline & 3 & $2 \%$ \\
\hline & 4 & $7 \%$ \\
\hline & 5 & $7 \%$ \\
\hline \multirow[t]{5}{*}{ Treatment-3 } & 1 & $70 \%$ \\
\hline & 2 & $6 \%$ \\
\hline & 3 & $8 \%$ \\
\hline & 4 & $5 \%$ \\
\hline & 5 & $11 \%$ \\
\hline \multirow[t]{5}{*}{ Treatment-4 } & 1 & $62 \%$ \\
\hline & 2 & $9 \%$ \\
\hline & 3 & $12 \%$ \\
\hline & 4 & $8 \%$ \\
\hline & 5 & $9 \%$ \\
\hline \multirow[t]{5}{*}{ Treatment-5 } & 1 & $70 \%$ \\
\hline & 2 & $8 \%$ \\
\hline & 3 & $6 \%$ \\
\hline & 4 & $6 \%$ \\
\hline & 5 & $10 \%$ \\
\hline
\end{tabular}

Figure 4. Mean shoot, root and total strawberry plant weights.

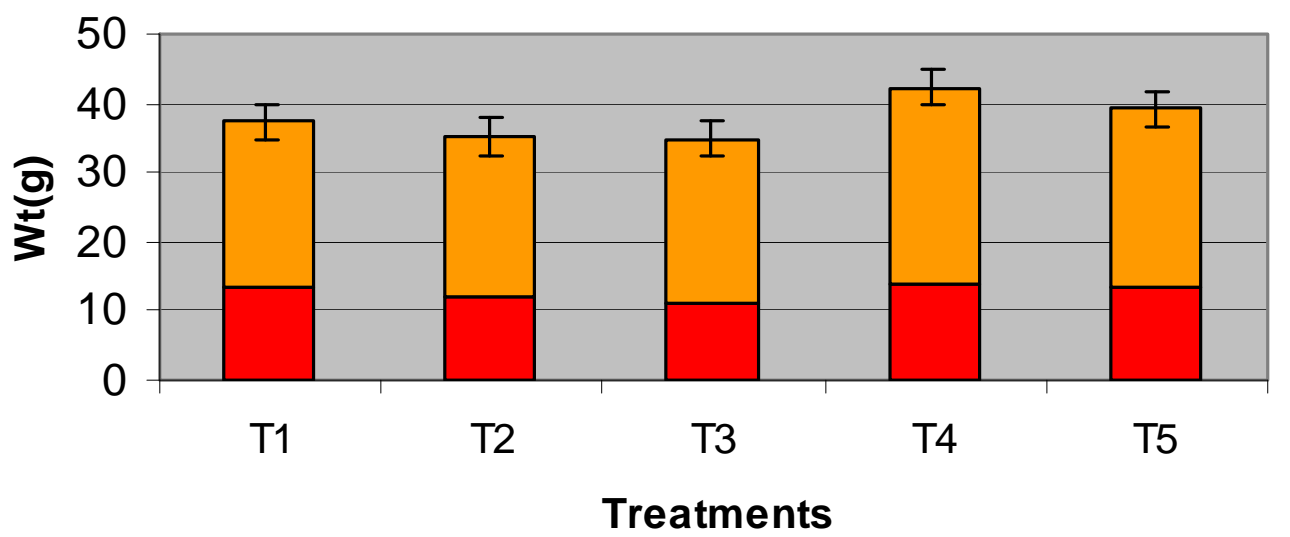

$\square$ Roots $\square$ Shoots

Bars represent the total mean plant weights $(\mathrm{g})$ of 10 replicate plants $( \pm \mathrm{SE})$, showing contribution of mean shoot and root weights for each treatment. 
Even though there were no significant differences, these results follow a similar trend to those obtained for the fresh fruit weights, with the two treatments consisting of soil inoculated with streptomycete isolates, Treatments 4 and 5, recording a higher harvested fruit weight than the other three treatments. Treatments $4(42.3 \mathrm{~g})$ and $5(38.1 \mathrm{~g})$ obtained the highest mean total dry plant weights, when compared to the controls Treatments $1(37.4 \mathrm{~g}), 2(35.2 \mathrm{~g})$, and to the treatment consisting of C3-LP-EtOAc extract, Treatment 3 (34.9 g) (Figure 4). In addition, differences existed between plants from Treatments 4 and 5 when visually compared to Treatments 1, 2, and 3 (Figure 4).

\section{Conclusions}

Fungal infections to strawberry fruit causing significant destruction to crops in the Sunshine Coast region result in significant economic losses to growers. Use of streptomycetes as potential biological control agents might be an alternative way to replace the currently used environmentally-unfriendly pesticides. Assays conducted in vitro have indicated that there was a strong antifungal action expressed by the streptomycete isolates against $B$. cinerea supporting the findings of other studies indicating similar antifungal actions by streptomycete species against different phytopathogens [30-33]. Although the ecological relevance and the lack of correlation to field performance of in vitro screening procedures utilised for establishing antagonism by the potential biocontrol organism are open to doubt, these procedures have proved useful in identifying potential biocontrol agents warranting further investigations in greenhouse and field studies [34]. For example, Trejo-Estrada et al. [31] established that $S$. violaceusniger YCED9 produced at least three antibiotics that inhibited fungal pathogens of turf grass in vitro. When greenhouse experiments were conducted, S. violaceusniger YCED9 controlled partially a grass seedling disease caused by Rhizoctonia solani and a crown-foliar disease caused by Sclerotinia homeocarpa. Similarly results obtained from the pot trial demonstrated that the observed antagonism in vitro was not reproducible in all cases when assessed under conditions more closely related to field conditions. Furthermore, more diseased fruit obtained in the streptomycete treated pots might indicate that some actinomycete metabolites perhaps convert the pathogen into more aggressive form such as the monosaccharide, flavin-like compound and valine fragments detected in the metabolites identified in the study. Interestingly, Schrey and Tarkka [35] recently documented the suppressive and promoter activity of the streptomycetes on plant pathogens and recommended caution in their selection and use as biological control agents.

Growth promotion of plants grown in a soil medium inoculated with streptomycete spp. has been commonly reported [36,37]. The mechanisms by which beneficial microorganisms promote plant growth include increasing available nutrients for uptake by the plant by recycling and solubilising mineral nutrients and the provision of plant growth substrates by the synthesis of vitamins, amino acids or plant hormone (e.g., auxins and gibberellins) [36,37]. Although a reduction in the incidence of fruit infected by $B$. cinerea by the streptomycete isolates used in this study was not apparent, they were found to significantly stimulate fresh fruit weights harvested from these strawberry plants when compared to fruit weights from plants grown in un-inoculated soil. Nature of the growth promoting compounds from the isolates warrant further investigation, and growth promotion induced by streptomycete species and their metabolites when applied externally to the fruit might be a bonus for the industry during the marketing of the fruit [38]. 


\section{Acknowledgements}

Authors thank Graham and Carol Wood for their support and assistance provided during sample collection at their farm and to Roger Shivas at DPI, Herbarium, Indooroopilly, Queensland for the identification of the Botrytis cinerea isolates.

\section{References}

1. Queensland Strawberry Industry. Available online: http://www.qldstrawberries.com.au/links.htm (accessed on 1 December 2010).

2. Strawberry $R \& D$ Update; Department of Primary Industries and Fisheries: Nambour, Australia, 2007. Available online: http://www.qldstrawberries.com.au/pdf/strawberry_update_2007.pdf (accessed on 1 December 2010).

3. Helbig, J. Biological control of Botrytis cinerea Pers. ex Fr. in strawberry by Paenibacillus polymyxa (isolate 18191). J. Phytopathol. 2001, 149, 265-273.

4. Kalamarakis, A.E.; Petsikos-Panagiotarou, N.; Mavroidis, B.; Ziogas, B.N. Activity of fluazinam against strains of Botrytis cinerea resistant to benzimidazoles and/or dicarboximides and to a benzimidazole-phenylcarbamate mixture. J. Phytopathol. 2000, 148, 449-455.

5. Dianez, F.; Santos, M.; Blanco, P.; Tello, J.C. Fungicide resistance in Botrytis cinerea isolates from strawberry crops in Huelva (southwestern Spain). Phytoparasitica 2002, 30, 529-534.

6. Freeman, S.; Minz, D.; Kolesnik, I.; Barbul, O.; Zveibil, A.; Mayon, M.; Nitzani, Y.; Kirshner, B.; Rav-David, D.; Bilu, A.; Dag, A.; Shafir, S.; Elad, Y. Trichoderma biocontrol of Colletotrichum acutatum and Botrytis cinerea and survival in strawberry. Eur. J. Plant Pathol. 2004, 110, 361-370.

7. Vagelas, I.; Papachatzis, A.; Kalorizou, H.; Wogiatzi, E. Biological control of botrytis fruit rot (gray mold) on strawberry and red pepper fruits by olive oil mill wastewater. Biotechnol. Biotechnol. Eq. 2009, 23, 1489-1491.

8. Rosslenbroich, H.-J.; Stuebler, D. Botrytis cinerea-History of chemical control and novel fungicides for its management. Crop Prot. 2000, 19, 557-561.

9. Szandala, E.S.; Backhouse, D. Suppression of sporulation of Botrytis cinerea by antagonists applied after infection. Australas. Plant Pathol. 2000, 30, 165-170.

10. Elad, Y. Mechanisms involved in biological control of Botrytis cinerea incited diseases. Eur. J. Plant Pathol. 1996, 102, 719-732.

11. Mommaerts, V.; Platteau, G.; Boulet, J.; Sterk, G.; Smagghe, G. Trichoderma-based biological control agents are compatible with the pollinator Bombus terrestris: A laboratory study. Biol. Control. 2008, 46, 463-466.

12. Atlas, R.M. Handbook of Microbiological Media, 2nd ed.; CRC Press: Boca Raton, FL, USA, 2006.

13. Kuster, E.; Williams, S.T. Selection of media for isolation of streptomycetes. Nature 1964, 202, 928-929. 
14. Williams, S.T.; Wellington, E.M.H. Actinomycetes. In Methods of Soil Analysis, Part 2. Chemical and Microbiological Properties, 2nd ed.; Miller, R.H., Keeney, O.R., Eds.; American Society of Agronomy: Madison, DC, USA, 1982; pp. 969-987.

15. Cross, T. Growth and examination of actinomycetes. In Bergey's Manual of Systematic Bacteriology; Williams, S.T., Sharpe, M.E., Holt, J.G., Eds.; Williams and Wilkins: Baltimore, MD, USA, 1989; Volume 4, pp. 2340-2344.

16. Shirling, E.B.; Gottlieb, D. Methods for characterization of Streptomyces species. Int. J. Syst. Bacteriol. 1966, 16, 313-340.

17. Wellington, E.M.H.; Williams, S.T. Preservation of actinomycetes inoculum in frozen glycerol. Microbios Lett. 1978, 6, 151-157.

18. Dhingra, O.D.; Sinclair, J.B. Basic Plant Pathology Methods, 2nd ed.; CRC Press: Boca Raton, FL, USA, 1995.

19. Gibbs, J.N. A study of the epiphytic growth habit of Fomes annosus. Ann. Bot. 1967, 31, 755-774.

20. Dennis, C.; Webster, J. Antagonistic properties of species-groups of Trichoderma II production of volatile antibiotics. T. Brit. Mycol. Soc. 1971, 57, 41-48.

21. Shimizu, M.; Nakagawa, Y.; Sato, Y.; Furumai, T.; Igarashi, Y.; Onaka, H.; Yoshida, R.; Kunoh, H. Studies on endophytic Actinomycetes (I) Streptomyces sp. isolated from rhododendron and its antifungal activity. J. Gen. Plant. Pathol. 2000, 66, 360-366.

22. Edwards, S.G.; Seddon, B. Mode of antagonism of Brevibacillus brevis against Botrytis cinerea in vitro. J. Appl. Microbiol. 2001, 91, 652-659.

23. Kurtboke, D.I.; Cardillo, R.; Nasini, G., Petrolini, B.; Sardi, P.; Locci, R. Anti-candida metabolites produced by streptomycetes isolated from the atmosphere of agricultural environments. In Actinomycetes; Lechevalier, H., Ensign, J.C., Kalakoutskii, L.V., Locci, R., Eds.; Waksman Institute of Microbiology-Rutgers The State University of New Jersey: New Brunswick, NJ, USA, 1986; pp. 223-231.

24. Kurtboke, D.I.; Shankar, M.; Rowland, C.Y.; Sivasithamparam, K. Responses of a sterile red fungus to soil types, wheat varieties and the presence of certain isolates of Streptomyces. Plant Soil 1993, 157, 35-40.

25. Agricultural Field Experiments; Petersen, R.G., Ed.; Marcel Dekker, Inc.: New York, NY, USA, 1994.

26. Swadling, I.R.; Jeffries, P. Antagonistic properties of two bacterial biocontrol agents of grey mould diseases. Biocontrol. Sci. Tech. 1998, 8, 439-448.

27. Archbold, D.D.; Hamilton-Kemp, T.R.; Barth, M.M.; Langlois, B.E. Identifying natural volatile compounds that control gray mould (Botrytis cinerea) during postharvest storage of strawberry, blackberry, and grape. J. Agr. Food. Chem. 1997, 45, 4032-4037.

28. Srihuttagum, M.; Sivasithamparam, K. The influence of fertilizers on root rot of field peas caused by Fusarium oxysporum, Pythium vexans and Rhizoctonia solani inoculated singly or in combination. Plant Soil 1991, 132, 21-27.

29. Synder, L.R. Classification of the solvent properties of common liquid. J. Chromatogr. 1974, 92, 223-230. 
30. Sutton, J.C. Evaluation of micro-organisms for biocontrol: Botrytis cinerea and strawberry. In Advances in Plant Pathology; Andrews, J.H., Tommerup, I.C., Eds.; Academic Press: London, UK, 1995; Volume 11, pp. 173-190.

31. Trejo-Estrada, S.R.; Rivas Sepulveda, I.; Crawford, D.L. In vitro and in vivo Antagonism of Streptomyces violaceusniger YCED9 against fungal pathogens of turfgrass. World J. Microb. Biot. 1998, 14, 865-872.

32. Tokala, R.K.; Strap, J.L.; Jung, C.M.; Crawford, D.L.; Hamby Salove, M.; Deobald, L.A.; Bailey, J.F.; Morra, M.J. Novel plant-microbe rhizosphere interaction involving Streptomyces lydicus WYEC108 and the pea plant (Pisum sativum). Appl. Environ. Microbiol. 2002, 68, 2161-2171.

33. Whipps, J. Microbial interactions and biocontrol in the rhizosphere. J. Exp. Bot. 2001, 52, 487-511.

34. Berg, G. Plant-microbe interactions promoting plant growth and health: Perspectives for controlled use of microorganisms in agriculture. Appl. Microbiol. Biotechnol. 2009, 84, 11-18.

35. Schrey, S.D.; Tarkka M.T. Friends and foes: Streptomycetes as modulators of plant disease and symbiosis. Antonie Leeuwenhoek 2008, 94, 11-19.

36. Compant, S.; Duffy, B.; Nowak, J.; Clement, C.; Barka, E.A. Use of plant growth-promoting bacteria for biocontrol of plant diseases: Principles, mechanisms of action, and future prospects. Appl. Environ. Microbiol. 2005, 71, 4951-4959.

37. Contreras-Cornejo, H.A.; Macias-Rodriguez, L.; Cortes-Penagos, C.; Lopez-Bucio, J. Trichoderma virens, a plant beneficial fungus, enhances biomass production and promotes lateral root growth through an auxin-dependent mechanism in Arabidopsis. Plant Physiol. 2009, 149, 1579-1592.

38. Morrissey, J.P.; Dow, J.M.; Mark, L.; O'Gara, F. Are microbes at the root of a solution to world food production? EMBO Rep. 2004, 5, 922-926.

(C) 2010 by the authors; licensee MDPI, Basel, Switzerland. This article is an open access article distributed under the terms and conditions of the Creative Commons Attribution license (http://creativecommons.org/licenses/by/3.0/). 